Revista Eletrônica do Mestrado em Educação Ambiental

\title{
O Movimento Negro enunciado em corporeidades, estéticas e histórias: construções e reconstruções sinestésicas por meio do filme Abolição no curso de Pedagogia.
}

Resumo: A presente pesquisa tem por objetivo problematizar a construção e a reconstrução de imagéticas por meio do filme Abolição (1988), de Zózimo Bulbul, por meio das categorias corpóreas, estéticas e históricas enunciadas por diversas personagens integrantes do Movimento Negro em uma perspectiva decolonial e da cultura visual no curso de pedagogia de uma universidade estadual localizada na Baixada Fluminense. Para isso, utilizamos a metodologia da videoinstalação, com o intuito de relacionar os conhecimentos estéticos e históricos às corporeidades das estudantes-espectadoras. $\mathrm{O}$ resultado da experiência suscitou práticas sinestésicas que proporcionaram novas reflexões para o currículo e didática do curso de formação de professores, voltadas às ressignificações das epistemologias afro-brasileiras.

Palavras-chave: Pedagogia decolonial; Movimento Negro; Sinestesias.

\section{El movimiento negro enunciado en corporealidades, estéticas e historias:}

\section{construcciones y reconstrucciones sinestésicas a través de la película Abolição en el}

\section{curso de la pedagogía}

Resumen: La presente investigación tiene como objetivo problematizar la construcción y reconstrucción de imágenes a través de la película Abolição (1988), de Zózimo Bulbul, a través de las categorías corporales, estéticas e históricas enunciadas por varios personajes del Movimiento Negro en perspectivas decoloniales y de la cultura visual en el curso de pedagogía de una universidad estatal ubicada en la Baixada Fluminense. Para esto, utilizamos la metodología de la videoinstalación, para relacionar el conocimiento estético e histórico con las corporeidades de las

\footnotetext{
${ }^{1}$ Doutor em Educação pela Universidade Federal do Rio de Janeiro (2018). Membro da Sociedade Brasileira de Estudos do Cinema (SOCINE) e da Rede KINO: Rede Latino-Americana de Educação, Cinema e Audiovisual. Licenciado em Pedagogia (2007) pela Universidade do Estado do Rio de Janeiro (UERJ). Atualmente, é professor auxiliar da Universidade Estácio de Sá (UNESA) na Licenciatura em Pedagogia. Docente do curso de Pós-Graduação Lato Sensu em Psicopedagogia Clínica e Institucional (UNESA). Coordenador do GINCF (Grupo de Pesquisa em Intelectualidade Negra, Currículo e Formação docente). e-mail: fabiojp83@yahoo.com.br
} 
estudiantes espectadoras. El resultado de la experiencia dio lugar a prácticas sinestésicas que proporcionaron nuevas reflexiones para el currículum y la didáctica del curso de formación docente, dirigido a la redefinición de las epistemologías afrobrasileñas.

Palabras clave: Pedagogía decolonial; Movimiento negro; Sinestesias.

\title{
The Black Movement enunciated in corporealities, aesthetics and stories: synaesthetic constructions and reconstructions through the film Abolição in the course of Pedagogy
}

\begin{abstract}
The present research aims to problematize the construction and reconstruction of imagery through the film Abolição (1988), by Zózimo Bulbul, through the corporeal, aesthetic and historical categories enunciated by several characters from the Black Movement in a decolonial perspective and visual culture in the course of pedagogy from a state university located in Baixada Fluminense. For this purpose, we use the methodology of video installation, in order to relate the aesthetic and historical knowledge to the corporealities of the student-spectators. The result of the experience gave rise to synaesthetic practices that provided new reflections for the curriculum and didactics of the teacher training course, aimed at the redefinitions of Afro-Brazilian epistemologies Keywords: Decolonial Pedagogy; Black Movement; Synesthesias.
\end{abstract}

\section{Introdução}

O presente artigo tem o objetivo de apresentar as experiências de construções e reconstruções imagéticas negras, por meio de videoinstalações em um curso de Pedagogia de uma universidade estadual, localizada no município de Duque de Caxias, na Baixada Fluminense. A experiência foi uma das atividades de uma pesquisa de doutorado em educação, com o objetivo de compreender a produção de presença negra por meio da cinematografia de Zózimo Bulbul. Para isso, buscamos desenvolver esta investigação com estudantes de uma disciplina eletiva voltada para problematizar o cinema enquanto arte na escola.

A justificativa para a escolha dessa instituição relaciona-se com os fundamentos teórico-metodológicos das decolonialidades e da cultura visual. Primeiro, o campus dessa universidade estadual está localizado no municío de Duque de Caxias, o terceiro mais populoso do estado do Rio de Janeiro, composto por uma população majoritariamente negra, entre pretos e pardos. É também uma cidade que há décadas sofre com a criminalidade urbana. Nesse sentido, pensar esse território como local para o desenvolvimento de pedagogias decoloniais é essencial para que essas futuras licenciadas em Pedagogia - em nosso caso majoritariamente mulheres negras - tenham condições de se reconhecerem enquanto pertencentes a uma sociedade produtora de epistemologias de suas vivências e existências. 
A pesquisa também encontrou respaldos na ementa da disciplina, construída pela própria regente da turma, cujos objetivos são: pensar e produzir aspectos visuais, espaciais e também afetivos por meio de registros imagéticos das periferias do Rio de Janeiro. Por isso, a escolha desse espaço de formação docente pareceu-nos condizente à proposta de pensar e produzir novas imagéticas por meio do cinema negro de Zózimo Bulbul.

No início das aulas, explicávamos brevemente sobre a trajetória artística desse cineasta e sua importância para o cinema nacional ao reconstituir outras estéticas para os negros e as negras. Dessa forma, nossa pesquisa, bem como o desenvolvimento curricular e didático de nossas aulas, esteve fundamentada na pedagogia decolonial. Essa perspectiva, segundo Walsh (2009), é entendida como processo educativo voltado às transmissões dos saberes e práticas sociopolíticas nos cotidianos e pelos movimentos sociais de sujeitos historicamente pertencentes às estruturas coloniais.

As pedagogias decoloniais, como entende Walsh (2009), são aquelas produzidas em diversos espaços: escolas, universidades, nos bairros, nas comunidades, nos movimentos sociais e na rua. Dessa forma, as decolonialidades mobilizam os sujeitos a questionarem, analisarem e intervirem com intuito de transformarem de forma insurgente os poderes, os saberes e os seres, enfim, a própria vida (WALSH, 2009). A produção de conhecimentos por meio de sociedades historicamente subjugadas em uma perspectiva decolonial é necessária para o fortalecimento de um corpo conceitual próprio fundamentado em intelectuais e ativistas e em suas estratégias de composição em redes (MIRANDA e RIASCOS, 2016).

A construção e a reconstrução das imagens dessas estudantes na pesquisa aqui apresentada também encontraram fundamentos curriculares e didáticos nos estudos da cultura visual, pois analisamos e produzimos - parafraseando Hernandez (2006) - imagens relacionadas às artes, à mídia e à vida cotidiana. Com o intuito de compreender como as perspectivas decoloniais e da cultura visual, por meio do cinema negro de Zózimo Bulbul, foram desenvolvidas nesta disciplina do curso de pedagogia, este artigo divide-se em três partes. A primeira apresenta o cinema negro enquanto perspectivas decolonial e de cultura visual na formação de professores. A segunda parte analisa alguns planos do documentário Abolição a partir das categorias corpóreas, estéticas e históricas. A última parte explica como, nas aulas do curso de pedagogia, essas categorias produziram novos conhecimentos nas licenciandas, participantes da pesquisa. 


\section{O cinema negro enquanto pedagogia decolonial e cultura visual}

As teorias decoloniais e de cultura visual nos permitem compreender o cinema negro enquanto parte dessas epistemologias negras mobilizadoras para repensar corporeidades, estéticas e histórias produzidas com e pelos próprios negros, em uma sociedade marcada imageticamente pelos estereótipos midiáticos.

Nas palavras de Carvalho e Domingues (2017), o cinema negro é ainda um conceito em construção e em disputa. Segundo os autores, esses conflitos se dão não apenas por sua diversidade, mas por tentar estabelecer em um contexto estético - tanto no sentido das imagens produzidas, quanto no sentido político - o que é um cinema efetivamente negro, capaz de romper estereótipos e produzir outras imagéticas.

Mercer (1994) já enunciava a tendência dos diálogos promovidos pelo cinema negro, enquanto um dos mais importantes princípios dessa constituição cinematográfica, pois renova as funções da crítica do cinema independente. Além disso, a promoção de oficinas e formações, de acordo com o autor, tem integrado diferentes modos de desenvolver o cinema negro, possibilitando aos cineastas da diáspora espaços para encontrarem diferentes pares e estabelecerem contatos com públicos variados, para formarem comunidades específicas cujo interesse recai em explorar novas estéticas negras.

Entendemos o cinema negro e sua intencionalidade de romper com as estéticas estereotipadas intrísecas aos anseios e desejos do Movimento Negro (MN), atuante desde o pós-abolição, compreendido como o conjunto de grupamentos, instituições e associações que lutam contra o racismo por meio de diversas estratégias culturais, políticas e educacionais. Dessa forma, o cinema negro de Zózimo Bulbul seria mais uma das manifestações do MN, com a intencionalidade de educar por meio das imagens.

Nessa perspectiva, o que o cinema negro enquanto expressividade do MN pode ensinar no processo de formação de professores? De acordo com Gomes (2017, p. 10): “Os movimentos sociais são produtores e articuladores dos saberes construídos pelos grupos não hegemônicos e contra-hegemônicos da sociedade brasileira. Atuam como pedagogos nas relações políticas e sociais." Entendemos o Movimento Negro como capaz de questionar a própria história construída em sua univocidade colonial na relação com o sistema capitalista, e ao mesmo tempo, produtor de conhecimentos inerentes à ancestralidade negra enquanto fundamentadora de novas concepções corpóreas, históricas e estéticas. 
Pensamos a formação de professores como mais um lugar de desenvovlimento comunitário cultural decolonial que, nas palavras de Miranda e Riascos (2016), suscita-nos a reelaborar nossas memórias coletivas. Isso exige, de acordo com as autoras, o reconhecimento por parte dos espaços de formação docente, assim como das escolas, de processos de educabilidade das populações afro-diaspóricas, ressignificadores dos conhecimentos curriculares e didáticos de diferentes linguagens artísticas, entre elas, as imagens cinematográficas.

No caso das populações africanas e afro-diaspóricas, uma celeuma se apresenta: como construir conhecimentos outros fundamentados em diferentes expressividades do MN, quando essas sociedades tiveram seus saberes destituídos nos processos coloniais? Nas palavras de Mignolo (2003), o epistemicídio foi uma das primeiras formas encontradas pelos colonizadores para dizimar diversas populações negras. Entretanto, Hall (2003) aponta-nos algumas questões sobre as presenças negras aproximadas pelas ausências. Para teórico jamaicano, quanto mais as populações negras reivindicam suas presenças, como forma de ser e estar no mundo, mais estabelecem relações "com aquilo que está ausente, não marcado, não dito, ou que é impronunciável” (HALL, 2003, p. 97).

Esses novos caminhos criados pelo, até então, inaudível e invisível, conduziram Zózimo Bulbul e os companheiros do cinema de outras diásporas a estabelecerem elos entre algo em comum - a ausência ancestral africana - e assim transformassem-se em presença, por meio do cinema. Dessa forma, “a co-presença espacial e temporal dos sujeitos anteriormente isolados por disjunturas geográficas e históricas [...] agora se cruzam" (HALL, 2003, p. 31).

Esse hiato tornou-se propício para a construção e a reconstrução das imagens, outrora desgastadas, para aproximar-se de imagens outras, capazes de resgatar as ancestralidades até então desconhecidas e possibilitar aos sujeitos negros o posicionamento de perspectivas coletivas pelos olhares subjetivos. Dessa forma, apostamos nas perspectivas da cultura visual para repensar e, ao mesmo tempo, produzir imagens afrodiaspóricas potencializadas por "maneiras subjetivas e intrassubjetivas de ver o mundo e a si mesmo" (HERNANDEZ, 2006, p. 21). Essas construções imagéticas possibilitam os sujeitos relacionarem suas corporeidades com o processo reflexivo, cujas produções se realizam por meio de subjetividades fundamentadas nas representações culturais de mundo.

$\mathrm{Na}$ busca de compreender esses diferentes conhecimentos imagéticos, capazes de inter-relacionar as subjetividades inspiradas pela ancestralidade africana e afro-brasileira, 
escolhemos para o desenvolvimento de uma das nossas atividades de videoinstalação o filme Abolição (1988), de Zózimo Bulbul. Observamos que o cineasta evidenciou nesta obra três importantes conceitos intrínsecos e indissociáveis na produção de presença negra: o corpo, a estética e a história. Essas categorias foram não somente analisadas nessa obra fílmica, como também apropriada enquanto currículo e didática na formação docente.

\section{Uma análise do filme Abolição: presença e criação corpórea, estética e histórica}

Abolição (1988) é um documentário dirigido e produzido por Zózimo Bulbul. O filme demonstra novas formas de analisar a produção de presença histórica de forma mais contundente, de acordo com as perspectivas das diferentes expressões do Movimento Negro que sempre contestaram suposta liberdade das populações negras.

Logo no primeiro plano², Zózimo escolhe imagens dos pintores, entre eles Jean Baptiste Debret e Johann Muritz Rugendas, responsáveis pela missão francesa a partir da chegada da família real ao Brasil, em 1808. Através dos quadros desses expoentes das artes plásticas do início do século XIX foram feitas interpretações do cotidiano dos negros em situação de escravidão. As imagens demonstram, em grande parte, cenas de subalternidade física nas quais as negras e os negros eram submetidos. Após um minuto e meio de pinturas que se alternam, são exibidas fotografias - provavelmente datadas do final do século XIX - com imagens de negros acorrentados, chicoteados e presos em redes, semelhante à ideia de capturar certa quantidade de peixes no mar.

Durante a exibição dessas tristes imagens, é enunciado o Canto I, interpretado por Clementina de Jesus, Tia Doca e Geraldo Filme, do álbum O Canto dos Escravos, de 1982, com referências às ancestralidades dos negros benguelas de São João da Chapada, distrito de Diamantina-MG:

\footnotetext{
Yao $\hat{e}$,

Ererê ai ogum bê.

Com licença do Curiandamba,

Com licença do Curiacuca,

Com licença do Sinhô Moço,

Com licença do Dono de Terra.
}

\footnotetext{
${ }^{2} \mathrm{Na}$ análise do filme, os planos foram enumerados. O plano é entendido neste texto como tudo o que se grava entre o momento em que a câmera é ligada até quando esta é desligada.
} 
O Canto I faz parte dos Vissungos - cantos de força enunciados pelos escravos africanos das regiões auríferas no período escravocrata brasileiro. Para suportar o pesado trabalho, o eu-póetico pede licença a Curiandamba - um ser sobrenatural, similar a Exu, orientador dos caminhos a serem seguidos - e a Curiacuca - aquele que cozinha e também sabe cantar.

As referências tanto aos espíritos africanos quanto aos subjugadores no campo da brutal realidade escravagista, revelam desde o início a interpretação para a necessidade de relacionar a esfera espiritual e o real, ou seja, o transcendente e o social constituem as vivências e existências ao mesmo tempo. Mas, da mesma forma como os cânticos vissungos foram se perdendo com o tempo, ao que parece, essa forma de não hierarquizar os conhecimentos também foi se tornando menos evidente na constituição da história das populações afro-brasileiras. Dessa forma, foi necessário produzir novos conhecimentos até então inaudíveis e invisibilizados. Essas intencionalidades já estão evidentes nos primeiros planos de Abolição, cujos aspectos do passado ainda constituíam o presente, seja para emancipar ou para ainda dar continuidade aos processos coloniais.

No plano 5, a equipe de filmagem chega ao antigo Palácio de Verão da Família Imperial, na cidade de Petrópolis-RJ, para iniciar as gravações. Em seguida, no plano 6, aparece a famosa pintura "Abolição da escravatura", de Victor Meirelles, com a imagem da Princesa Isabel. Aos poucos, a obra de arte vai sendo ampliada como se a câmera do plano anterior estivesse documentando aquele momento histórico. Já no plano 7, a atriz Camila Amado, interpretando a própria Isabel, está em meio às autoridades, após assistirem a assinatura do decreto abolicionista. Aos poucos, Isabel caminha em direção à sacada do palácio, levando consigo o documento. Enquanto caminha, passa as mãos pelo tórax, como se quisesse se libertar de algo que a sufocava. Ao chegar à sacada, começa a bradar, para ser ouvida por todos: a escravidão, a partir daquele dia, estava extinta. Ao terminar de gritar, levanta as mãos para o alto.

O plano 8 mostra o desfile de uma escola de samba na Marquês de Sapucaí, no Rio de Janeiro. Os integrantes da agremiação, majoritariamente negros, são evidenciados como se estivessem comemorando suas supostas liberdades a partir do 13 de maio, cujas imagens altenam-se com a de Isabel assistindo a abolição carnavalesca. Os corpos negros evidenciados, logo em seguida, voltam a realidade, ao caminharem da Marquês de Sapucaí para o terminal de trens, na estação Central do Brasil. Sobre a imagem de um folião que carrega partes de suas fantasias, ao final do desfile, com menos entusiasmo das horas 
anteriores, aparece uma tarja horizontal vermelha com o nome do filme Abolição, em letras pretas.

A cor vermelha pode trazer várias conotações, pois lembra o sangue derramado sobre a vida de vários negros. Concomitantemente, também, nos apresenta as contradições desse processo entre as questões da liberdade e das opressões. Quando surge ao fundo a imagem do folião, podemos compreender a liberdade, mas acima dele aparece a tarja vermelha, reiterando a opressão. Em seguida, sob a tarja vermelha apresenta-se a palavra "Abolição", sinônimo da liberdade, mas dentro do vocábulo, a primeira letra "o" é composta pela cabeça de um negro em situação de escravidão, capturado por meio de uma rede.

As escolhas estéticas desse plano remetem-nos ao pensamento subjetivo do cineasta e ele nos interroga: até que ponto a liberdade ocorreu? Parece-nos que houve uma liberdade até um determinado ponto e em meio à vida após a suposta abolição, os subjugamentos continuam a prevalecer. Em seguida, aparecem outros foliões em direção à Central do Brasil e, com essas imagens, Bulbul dedica a produção da obra às suas referências: ao mestre Glauber Rocha e Leon Hirzman, os expoentes do Cinema Novo, com os quais o próprio cineasta trabalhou. Em seguida, dedica o filme ao cineasta Hermínio de Oliveira. Por último, dedica o filme ao Movimento Negro Unificado do Brasil (MNU).

Com vistas a ampliar o espectro das análises dos processos pós-abolição, o diretor dedica o filme ao cineasta negro Hermínio de Oliveira, fazendo uma relação com as próprias perspectivas de Bulbul, ao qual teve a constante necessidade de dialogar com os pares da diáspora também preocupados em produzir novas fontes de conhecimento por meio das imagéticas negras. A referência ao MN traz a fundamentação de Zózimo para a produção desse documentário com o intuito de reconstruir a história do Pós-Abolição pelas vozes das negras e dos negros.

A participação de intelectuais em sua maioria provenientes da militância possibilita a produção de uma presença histórica composta por novas corporeidades diferentes da alegria fugaz da festa do momo. Os contatos visuais e auditivos com pensadores negros, em Abolição, possibilitam aos espectadores estarem atentos ao mundo para construírem novas sensibilidades, retomando a característica da oralidade como uma das primeiras formas de aprendizagem das culturas africanas e afro-brasileiras.

De acordo com Gumbrecht (2010), o desejo de presença leva os sujeitos a imaginarem como se relacionariam intelectualmente com os seus corpos e com 
determinados objetos ao invés de simplesmente perguntar o que eles querem significar, como se estivessem em um passado sem relações com o presente. Assim, na perspectiva da cultura visual, ter as próprias referências culturais - neste caso, os intelectuais negros presentes no documentário Abolição - permite "às crianças, jovens, famílias e educadores olharem-se e serem olhados" (HERNANDEZ, 2006, p. 21).

Podemos compreender esse novo posicionamento no plano 18, no qual o professor Muniz Sodré, da Faculdade de Comunicação da Universidade Federal do Rio de Janeiro inicia sua fala, sentado à sua mesa em uma sala de aula. Atrás de Sodré, há um quadro verde escrito em giz "Abolição: uma farsa?". Em seguida, o professor caminha pelos corredores da faculdade, explicando sobre a Lei Áurea ao qual não trouxe nenhuma intencionalidade de inserir os libertos no sistema agrário. Ao contrário, os negros ficaram sem um lugar definido, ocupando uma massa de desempregados, como uma população flutuante, entre a cidade e o campo. Durante a explicação, Sodré apresenta um tom professoral. A intencionalidade é reiterada pelo ambiente universitário, mas também confirmada por seus gestos, nos quais as mãos acompanham seu discurso como se, naquele momento, muitos alunos estivessem junto dele.

Em seguida, a pesquisadora Beatriz do Nascimento lembra que a abolição de 1888 foi efetivada por causa da entrada do Brasil no sistema capitalista ao final do século XIX. A maneira firme e ao mesmo tempo tranquila da entrevistada é uma forma de instituir em sua corporeidade o apagamento daquela história narrada para outra estética. Ela deixa claro: apesar das opressões ainda existentes, as populações negras seguem rompendo com os estereótipos e consequentemente com as subalternizações. A construção estética da força e da vitalidade de Nascimento demonstra mais uma vez as questões referentes à liberdade, à vida e à existência como constituintes das populações negras.

A contraposição demonstrada pelos intelectuais negros em Abolição produz novas epistemologias legitimadoras da presença negra assumida de modo inerente pelos sujeitos pertencentes a essa raça e ao mesmo tempo esses se fazem produtores de novas teorizações, capazes de problematizar os silêncios históricos causadores dos ocultamentos.

No plano 28, o historiador João Rufino problematiza as resistências negras do início do século XX ao apresentar a Pedra do Sal, local onde as mulheres baianas habitaram em sua chegada ao Rio de Janeiro, e plantaram seu axé, acolhendo o samba e o candomblé como referências ancestrais. Rufino explica a condição de existência e de presença negra condicionada ao axé (ou asè, em ioruba), que significa energia vital na crença dos Orixás. É importante notar nesse plano, a consideração de Rufino sobre como 
essa energia é conduzida pelas mulheres, relembrando as sociedades africanas fundamentadas na matrilineariedade. Segundo o intelectual, elas são as guardiãs da ancestralidade a quem se deve primeiro ouvir, seguir e obedecer.

No plano 30, sentado sobre a Pedra do Sal, Rufino continua a ensinar sobre a importância dos espaços de resistências da população negra no Rio de Janeiro. Ali também elas faziam seus cultos e um local de encontro, onde surge o samba. A aula de Rufino é tematizada para compreendermos a intrínseca relação entre o transcendente e o real. Rufino continua a problematizar essa relação, ao explicar o posicionamento das mulheres e dos homens nas culturas afro-brasileiras:

A relação entre as tias baianas com os seus afilhados eletivos, alguns parentes de sangue, mas a maioria, escolhidos, como está na boa tradição negra africana. Essa relação é uma relação de sustentação, um sustentava o outro. Essas tias é que tornaram possível a esses afilhados eletivos terem um pouso onde comerem, onde dormirem, eventualmente e onde eles produziam a sua arte. Você tem aí uma associação muito comum na tradição negra africana e negra brasileira, profunda entre a mulher de idade, a mulher senhora do seu espaço e o homem. Ela representa a raiz, o assentamento, o fixo, a estabilidade, ele é o eventual, o que está solto no mundo, é o que está ali. É uma espécie de associação entre a prisão e a liberdade, entre o estar e o não-estar no mundo. Dessa associação é que vai nascer essa beleza criada por esses caras que ficaram conhecidos como malandros, malandros sim, pois souberam viver nas condições as mais difíceis, souberam tirar partido de elementos pequenininhos... Sobreviveram e deixaram uma descendência de compositores, de artistas, de agentes que deixaram o samba carioca plantado e estabelecido como parte da cultura brasileira para todo sempre (ABOLIÇÃO, 1988).

A aula dada por Rufino na Pedra do Sal reitera mais uma vez o conhecimento fundamentado em epistemologias africanas e afro-brasileiras. A primeira delas se refere ao posicionamento da mulher negra como o sustento e onde os homens poderiam encontrar nela o abrigo para continuarem a seguir suas vidas de incertezas e riscos. Apesar de grande parte dos sambistas e compositores serem homens, as mulheres são as guardiãs do samba enquanto continuidade da ancestralidade.

No plano 31, Rufino reitera sua exposição, ao apresentar a senhora Carmen Teixeira da Conceição, mais conhecida por Tia Carmen, como uma das principais referências da Praça Onze - outro principal local de preservação da ancestralidade brasileira e do surgimento do samba carioca. Segundo o historiador, essa anciã foi a responsável por resistir à exploração e à mercantilização do samba.

Apesar dela não se pronunciar e apenas balançar a cabeça, concordando com as palavras do pesquisador, há uma construção estética na qual a mulher é a imagem da 
guardiã do conhecimento ancestral. Há um elo estético reiterado por essa epistemologia entre a raiz, sustentada pela mulher negra, e a eventualidade do ser masculino.

Enquanto Tia Carmen está vestida de branco, com uma espécie de véu sobre a cabeça, e delicadamente com as mãos pousadas no parapeito da janela de sua casa, Rufino está abaixo, também vestido de branco, mas com uma vestimenta despojada e com uma boina personificando o próprio malandro. Ele está na calçada, pode sair. Tia Carmen está dentro de casa, para continuar a resguardar, com seu olhar e suas bençãos aos que ali chegam para construir a memória ancestral. Mais um plano no qual Zózimo consegue presentificar a história sob a ótica das negras e dos negros em seus próprios corpos.

No plano 32, a pesquisadora $\mathrm{X}^{3}$ apresenta a situação das mulheres negras no pósabolição. Essas, na verdade, continuam na mesma situação (ou bem pior) do período escravocrata, pois agora elas lutariam praticamente sozinhas por sua sobrevivência e a de seus filhos, fazendo delas os sustentáculos de suas famílias. Em um tom professoral, e ao mesmo tempo firme, a pesquisadora conclui:

Hoje, exatamente depois de cem anos de abolição, oitenta e três por cento das mulheres negras nesse país recebem menos de um salário mínimo. Esta é a liberdade que a mulher negra conhece. Qual é a diferença? Onde está a liberdade? (ABOLIÇÃO, 1988).

Os questionamentos da pesquisadora se articulam ao pensamento da historiadora e antropóloga Lélia Gonzales. No plano 60, Gonzales aparece sentada em uma poltrona e iluminada apenas pela luz do sol incidida sobre ela em sentido diagonal. Em torno dela, vemos apenas a cor escura do espaço, como se mais uma vez, o olhar cinematográfico de Bulbul quisesse deter apenas a atenção na oralidade das intelectuais. Assim, o importante nesse plano é estar atento ao que será enunciado.

De forma tranquila, Gonzales explica como os ganhos das populações negras no pós-abolição foram ínfimos, visto que os poderes políticos estão nas mãos de famílias brancas, dificultando a comunidade negra de se fazer presente nos espaços de decisão política. Por isso, o Movimento Negro, nas palavras de Gonzales, deveria ser o articulador político junto às comunidades de menores poderes aquisitivos, onde se encontra grande parte das populações negras, para torná-las mais confiantes em seus representantes.

Consciente dessa necessidade de buscar o passado para compreender o presente, Bulbul demonstra em Abolição a potencialidade das oralidades como canais por meio dos quais as corporeidades e diferentes estéticas podem ser evidenciadas por novas

\footnotetext{
${ }^{3}$ Alguns dos participantes do documentário não têm seus nomes apresentados. Por isso, nomeamos-os apenas com letras.
} 
epistemologias, colocando em xeque a própria história. Dessa forma, o documentário apresenta o posicionamento do cineasta em busca de reestabelecer uma pedagogia da memória ancestral imagética pensada, problematizada e reconceituada pela intelectualidade negra.

Dessa forma, o último plano de Abolição apresenta essa querela, ao captar imagens de vários transeuntes ao final de uma tarde na estação de trens da Central do Brasil, no Rio de Janeiro. A câmera vai se afastando de um grupo de trabalhadores defronte ao portão da estação terminal e, em seguida, o foco vai abaixando de forma que o enquadramento da imagem desse último plano ficasse posicionado atrás de uma grade, questionando se ainda as populações negras estão aprisionadas.

\section{Produção de presença negra em um curso de pedagogia: videoinstalação “Corpos sobre Abolição"}

A videoinstalação foi uma das práticas de produção de presença negra com a utilização das imagens nesta pesquisa. Esse exercício cinematográfico torna os espectadores em produtores, ao mesmo tempo em analisadores de duas ou mais imagens em projeção e/ou interagindo com elas:

Filha do casamento da instalação com a videoarte, fazendo uso das imagens em movimento na construção de uma obra de arte, a videoinstalação propõe algumas mudanças na postura do espectador, que passa a transitar entre as formas de apreciação da obra visual e do espetáculo. (COHN, 2016, p. 117).

Esse exercício cinematográfico possibilitou às graduandas serem artífices dos conhecimentos por elas produzidos:

As instalações de vídeo propõem ao espectador as duas atitudes, simultaneamente. Ao mesmo tempo em que elas mostram imagens em movimento, exigindo tempo de observação por parte do espectador, também o colocam em movimento, ao ocuparem o espaço tridimensionalmente, convidando o espectador a ser ativo no direcionamento do olhar e na relação que estabelece com o ambiente onde se situa a obra (que pode contar com várias telas, monitores ou outros suportes para as projeções, além da adição de objetos no espaço instalativo). (COHN, 2016, p. 117).

Dessa forma, a experiência de compor videoinstalações cujas licenciandas se posicionem enquanto intelectuais de suas próprias análises imagéticas, ampliou as epistemologias africanas e afro-brasileiras enquanto mobilizadoras constantes das 
corporeidades, das estéticas e das histórias fundamentadas em suas existências. Para isso, as videoinstalações inter-relacionaram as corporeidades e as imagens cinematográficas inseridas na perspectiva da cultura visual em que se apresentaram como alternativas para produções imagéticas por meio das tecnologias virtuais (HERNANDEZ, 2006).

Ao produzirem conhecimentos outros, a videoinstalação - como prática curricular e didática - reelaborou a história no momento em que os corpos das estudantes eram inseridos nas imagens fílmicas projetadas. Dessa maneira, o corpo pode ser entendido como campo de produção imagética e de análise (HERNANDEZ, 2006). Por conseguinte, a videoinstalação é entendida, nesta pesquisa, como uma pedagogia da imagem, uma vez que "ensina na medida em que ela, tanto do ponto de vista formal quanto de conteúdo, veicula um pensamento encorajando assim o pensamento no espectador." (LEANDRO, 2001, p. 34).

Cohn (2016) considera a experiência da videoinstalação a oportunidade para o corpo ser convocado e desestabilizado por pontos de vista habituais, provocando a criação de novos olhares. Dessa forma, o conhecimento emanado da videoinstalação não é um objeto distanciado do sujeito, mas uma ação física que:

[...] já estaria aí sugerida a partir da própria configuração da obra e de sua inscrição no espaço, mas não é só na atitude corporal que esse tipo de obra possibilita uma postura ativa e participante: a videoinstalação atua no universo perceptivo do seu espectador, nele encorajando sua condição de criador e construtor de conceitos (COHN, 2016, p. 117).

A videoinstalação permite aprender exercitando corporeidades mobilizadoras de atenção e, ao mesmo tempo, o deslocamento por meio das imagens, às quais o espectador possa repensar conhecimentos vistos e ditos. Dessa forma, a videoinstalação exercitada nesta pesquisa pretendeu ampliar pensamentos, sentimentos e interpretações incentivando os sujeitos a se presentificarem enquanto espectadores-participantes dos fragmentos do documentário Abolição.

Nessa perspectiva, o ato de ver e ouvir necessariamente não acontece exclusivamente pelos olhos e pelos ouvidos, respectivamente. Passamos então a refletir sobre como as corporeidades poderiam exercitar a captação dos olhares e das vozes negras por outros sentidos diferentes. Dessa forma, questionamos a possibilidade de desenvolver compreensões corpóreas, estéticas e históricas por meio de experiências sinestésicas, como por exemplo, ver pelo escutar ou ouvir pelo tocar. O nosso objetivo foi trazer para o contexto da formação docente as corporeidades, as produções imagéticas e estéticas 
fundamentadas nas epistemologias africanas e afro-brasileiras, presentes no filme Abolição, rompedoras de paradigmas, pois

[...] compreende que não há hierarquias entre conhecimentos, saberes e culturas, mas, sim, uma história de dominação, exploração, e colonização que deu origem a um processo de hierarquização de conhecimentos, culturas e povos. Processo esse que ainda precisa ser rompido e superado e que se dá em um contexto tenso de choque entre paradigmas no qual algumas culturas e formas de conhecer o mundo (GOMES, 2012, p. 102).

Dessa forma, quisemos iniciar um processo de superação dos conhecimentos dissociados pela dominação eurocêntrica para compreender como os próprios corpos são capazes de expressar o que ouvem e veem por diferentes sentidos. Da mesma forma como nas culturas africanas e afro-brasileiras se buscaram (e se buscam) constantemente a não hierarquização dos saberes, compreendemos também a não existência de uma sobreposição de sentidos e não limitações de suas expressividades.

Nessa experiência, as licenciandas experimentaram a sensação de estarem participando dos filmes por meio de experiências sinestésicas, pois foram inseridas corporalmente sobre as imagens e mesclaram diferentes sentidos analítico-corpóreos. Para isso, escolhemos alguns fragmentos de Abolição aos quais apresentavam algumas intelectuais, em sua maioria mulheres negras. A escolha pelas intelectuais negras se deu principalmente pelo fato das nossas experiências serem desenvolvidas para $\mathrm{o}$ reconhecimento das identidades negras das licenciandas.

Essa relação de reconhecimento, reflexão e produção das epistemologias feministas negras para com a experiência das espectadoras fazem com que essas estudantes se olhem e se vejam e, assim, produzam histórias em que elas sejam "uma contramemória, usando-a como forma de conhecer o presente e inventar o futuro" (HOOKS, 2018, p. 258). Por isso, para Mercer (1994), o cinema negro está estrategicamente ancorado nas questões sobre as dialéticas de raça, classe e especialmente inerentes ao gênero e à sexualidade. Nessa perspectiva, Hernandez (2001), por meio da cultura visual, considera que os sujeitos devem produzir análises tanto críticas quanto performativas e posicioná-las ativamente nos processos de decisões e resistências acerca da forma como desejam se enunciar imageticamente.

Com esse intuito, iniciamos a experiência da videoinstalação explicando às estudantes-participantes que elas seriam inseridas nos fragmentos projetados do filme Abolição. Dessa forma, ficariam de costas para as imagens. Optamos pela não visualização das imagens antes das experiências de inserção corpórea com a projeção do documentário. 
Dessa forma, a videoinstalação, enquanto currículo e didática do cinema negro de Zózimo Bulbul possibilitou processos de ensino e aprendizagens com e pelas imagens por diferentes sentidos. Essa experiência possibilitou às estudantes, parafraseando Leandro (2001), uma formação visionária de educadores que, como os cineastas, devem ver antes de enunciar as imagens. Dessa maneira, exercitamos essa capacidade de ver antecipadamente por movimentos sinestésicos, como também a capacidade de reflexão proposta na videoinstalação por meio das corporeidades.

\section{Corporeidades, histórias e estéticas sobre Abolição}

A videoinstalação foi nomeada pelas estudantes por Corporeidades, Histórias e Estéticas sobre Abolição. A ideia era potencializar as corporeidades das estudantes na interação com alguns fragmentos do documentário. Afinal, a videoarte sempre utilizou imagens que buscavam inserir o corpo do espectador nas imagens filmadas. A ideia desse dispositivo é permitir inicialmente ao artista entrar em relação com sua imagem, fazendo do dispositivo videográfico um modelo narcísico no qual "o espectador pode também ser implicado nesse mecanismo" (COHN, 2016, p. 146). No entanto, quando exercitamos a inserção das estudantes nas imagens do filme, possibilitamos um rompimento da ideia do que estava entre, para uma composição do que está nas imagens. Isso implica uma mudança de pensamento sobre como vemos e reconhecemos o corpo "implicado, tanto na convocação do espectador pela presença do objeto no espaço que habita, como quando a anatomia humana é aludida pela própria relação objeto-imagem" (COHN, 2016, p. 161). Como explica Leandro (2001), o material audiovisual didático é aquele que ensina o espectador a resistir à estética dominante e possibilita a construção de um pensamento crítico. Dessa forma, as imagens são formadas por corpos e pensamentos analisadosproduzidos quando o espectador e o cinema se inter-relacionam, produzindo novas imagéticas.

Com esse intuito, escolhemos três fragmentos de Abolição, nas quais estão presentes as intelectuais negras Lélia Gonzales, a pesquisadora X e o intelectual negro Muniz Sodré. Ao projetarmos na parede a imagem desses estudiosos, foi solicitado às três estudantes que ocupassem uma parte da tela para as suas imagens ficarem inseridas no enquadramento do plano. Em alguns momentos, conseguíamos evidenciar mais as imagens das próprias estudantes e, em outros, evidenciavam-se as sombras dos corpos. 
A primeira videoinstalação ${ }^{4}$ tinha por fundo de projeção o plano no qual o professor Muniz Sodré está sentado em uma das salas de aula da Faculdade de Comunicação da UFRJ, e explica sobre a farsa do processo abolicionista. A sombra projetada pela imagem da Estudante $A$ sobre o plano fílmico compõe um espaço da sala de aula na qual Sodré aborda a sua explanação. A composição dessa imagem leva-nos a compreender que a Estudante $A$ está ao fundo da sala de aula, assistindo à fala do professor, atentamente.

No plano seguinte, o docente caminha e explica sobre esse lugar indefinido, ao qual o negro ficou subjugado após a abolição na sociedade brasileira. A Estudante $A$, por meio de sua sombra, começa a procurar, ao lado de Sodré, esse negro sem um espaço definido na sociedade. A própria sombra da silhueta da estudante compõe em si a dúvida e o ocultamento daqueles aos quais foram omitidas suas existências. Assim, a Estudante $A$ é, ao mesmo tempo, quem busca e o próprio ser encontrado, agora, no espaço universitário, antes apenas ocupado pelas elites e agora também apropriado pelas populações diaspóricas. Nessa análise imagética, vislumbramos uma das potencialidades da cultura visual, no momento em que a estudante A relaciona os significados das práticas sociais e das relações de poder e, assim, busca rompê-las para, assim, olhar e ser olhada (HERNANDEZ, 2006).

A segunda videoinstalação mostra uma das pesquisadoras do documentário em uma praça pública, explicando a precariedade da situação da mulher negra após a abolição. Ao imergir na imagem, forma-se sobre os olhos da Estudante B uma tarja preta, como se essa mulher negra enunciada pela pesquisadora estivesse encoberta, lembrando um artifício usado pelos telejornais para não identificar uma pessoa. Nesse caso, a imagem da mulher negra é indefinida na sociedade brasileira.

Em outro momento, os galhos das árvores do plano fazem sobre o rosto da Estudante B uma série de riscos vistos como um tipo de cerca em volta do rosto, impedindo-a de ser uma mulher plena em sua liberdade, em consonância com a fala da pesquisadora. Essas relações imagéticas ocorrem exatamente no momento em que a estudiosa explica como a situação da mulher negra na contemporaneidade está a mesma de antes do processo abolicionista de 1888 .

\footnotetext{
${ }^{4}$ Por problemas técnicos durante a gravação, as imagens dessa videoinstalação não foram captadas.
} 
Figura 1: Videoinstalação "Corpos, estéticas e histórias sobre Abolição" - Fragmento I.

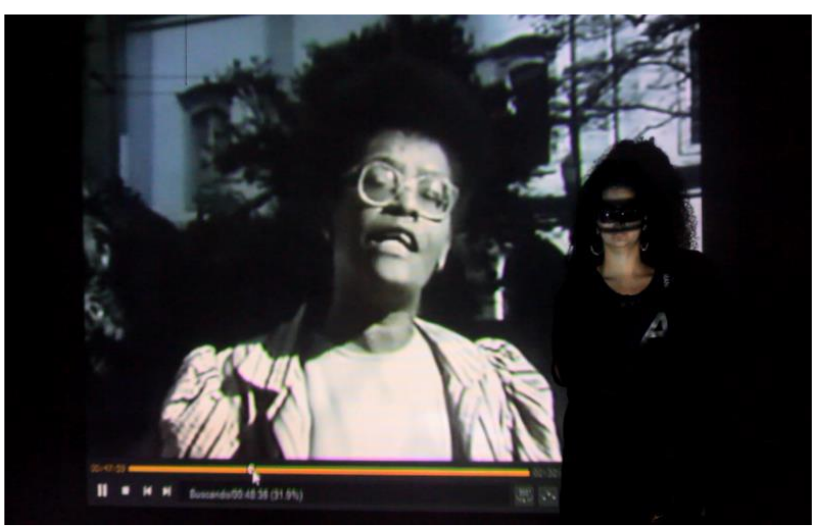

Fonte: arquivo de pesquisa.

Quase ao final da videoinstalação, a Estudante B compreende que a única forma de alcançar essa liberdade - por sinal questionada pela pesquisadora ao afirmar que $83 \%$ das mulheres negras do país recebem menos de um salário mínimo - é impondo-se em luta, ao fazer o gesto de braço levantado e punho cerrado, lembrando a saudação do movimento dos Panteras Negras, nos Estados Unidos, em meados da década de 1960.

Figura 2: Videoinstalação "Corpos, estéticas e histórias sobre Abolição" - Fragmento II.

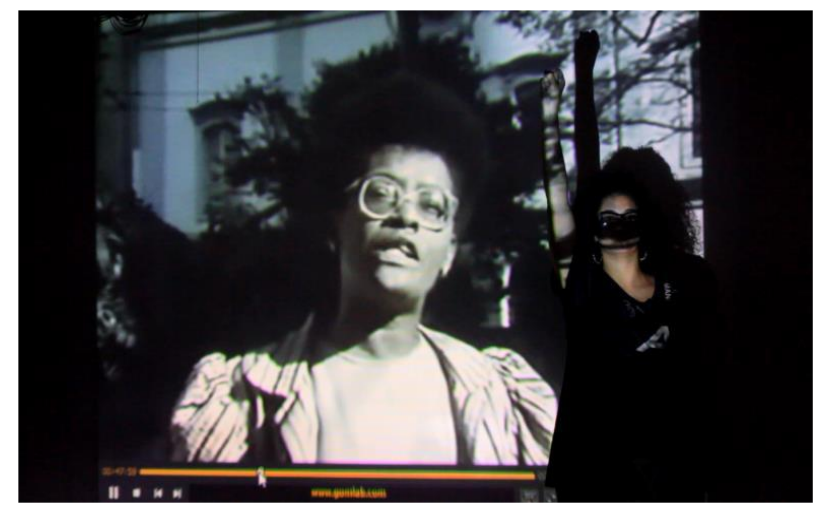

Fonte: Arquivo de pesquisa.

Essa visualidade demonstra sinestesicamente a capacidade de olhar pelo ouvir e deixar-se sentir pelo ver, a partir do momento em que a estudante B toma a decisão de fazer parte dessa luta com sua corporeidade. Em consonância com a educabilidade decolonial, essa corporeidade aprende a se posicionar no mundo, ao entrar em consonância com os conhecimentos proferidos pela intelectual X. Depreendemos dessas imagens a potencialidade da cultura visual ao relacionar novas estéticas de mulheres negras em 
diálogos com outras mulheres negras. Dessa forma, evidenciam-se novas imagéticas nas quais as mulheres analisam e evidenciam suas existências em seus próprios corpos.

A terceira videoinstalação apresenta a pesquisadora Lélia Gonzales explicando como os ganhos financeiros dos negros reduziram entre a abolição e a pós-abolição. Nesse momento, a Estudante $\mathrm{C}$ cerra os punhos e os mantém levantados, representando o sofrimento das populações negras, mas ao mesmo tempo resistindo.

Figura 3: Videoinstalação "Corpos, estéticas e histórias sobre Abolição" - Fragmento III.

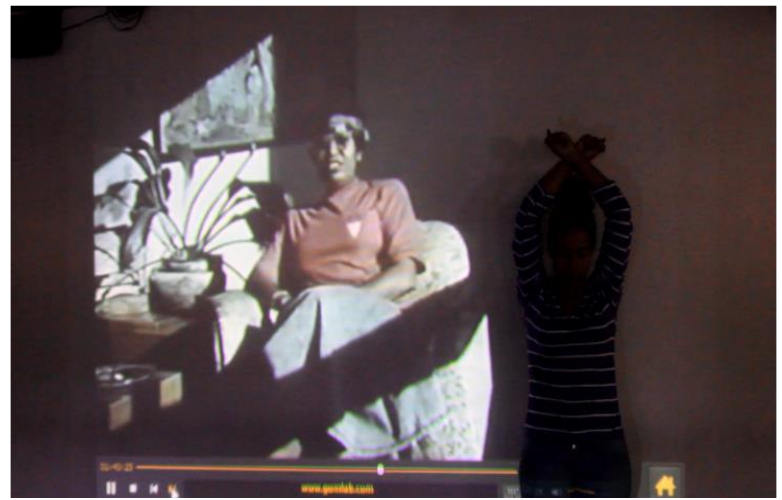

Fonte: Arquivo de pesquisa.

Quando Gonzales explica sobre a necessidade do Movimento Negro estabelecer estratégias para as populações negras tornarem-se mais confiantes em seus pares, a Estudante $\mathrm{C}$ abre os braços, mas ainda com os punhos cerrados, indicando a liberdade para colocar-se em luta.

Figura 4: Videoinstalação "Corpos, estéticas e histórias sobre Abolição" - Fragmento IV.

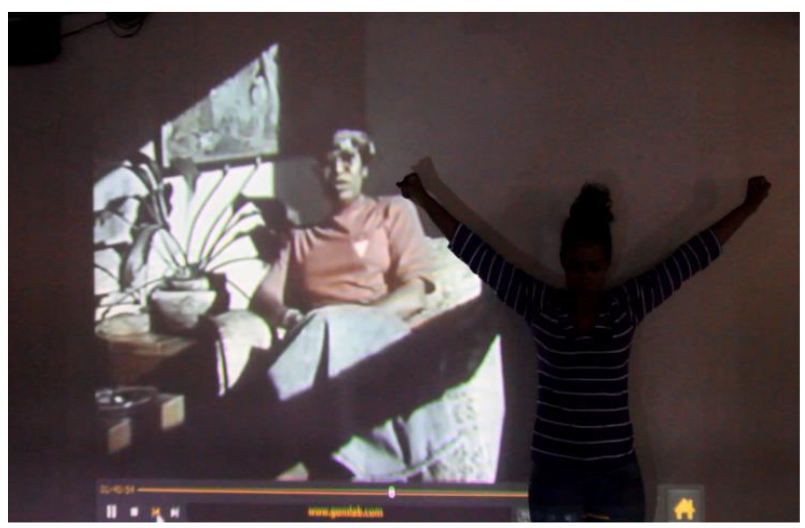

Fonte: Arquivo de pesquisa. 
Através dessa corporeidade, a visualidade efetiva-se pela participação da Estudante $\mathrm{C}$ nesse processo de refletir sobre sua condição enquanto mulher e negra. $\mathrm{O}$ corpopensamento dessa estudante é convocado a apresentar-se em si próprio pelos conhecimentos aos quais revisam a história, agora enunciada e construída pelas intelectuais negras. Esses novos conhecimentos quando encontram as corporeidades dessas estudantes produzem fundamentações às quais as visualidades são construídas para tomadas de decisão para romper com as possibilidades de opressão.

\section{Considerações finais}

A experiência com o cinema negro de Zózimo Bulbul nesse curso de pedagogia, a partir da videoinstalação, proporcionou às estudantes a produção de presença por meio de histórias e estéticas ressignificadas pelas corporeidades. Ao interagirem com as imagens de alguns ativistas e intelectuais do $\mathrm{MN}$, as estudantes imergidas nas imagens do filme buscaram ressignificar essas problemáticas por meio das interpretações sinestésicas nas quais seus corpos expressavam também parte dessas dificuldades, mas também expressões que colocavam seus corpos em consonância com lutas e a superações. Assim, ao lado de Muniz Sodré, ao explicar a situação de um não lugar dos negros no processo pós-abolição, a Estudante A continua a procurar as populações negras ainda perdidas. A Estudante B cerra os punhos quando outra intelectual fala dos ganhos ínfimos das mulheres negras após o processo abolicionista. E a Estudante $\mathrm{C}$ coloca-se em posição de luta ao dialogar com Lélia Gonzales sobre a necessidade de reorganização da população negra diante a um sistema político que a retirava dos locais de representatividade.

Nesse caso, as análises se efetivaram quando as interpretações sinestésicas possibilitaram outras formas de as estudantes estarem atentas ao enunciado pelos intelectuais do filme Abolição. Assim, possibilitar outra interpretação no caso das análises em sinestesia fez as estudantes estabelecerem um encontro com suas corporeidades enunciadas em si, de um sentido pelo outro. Ao exercitarem a audição pelo tato, o ver pela audição, deixaram-se conduzir pela vibração das vozes das intelectuais para, assim, reconhecerem em seus corpos o que deveria ser sentido e expressado.

Essas sinestesias reverberaram a potência dessa pedagogia decolonial imagética capaz de produzir diferentes olhares sobre a história das mulheres negras. Dessa forma, as estudantes presentificaram os discursos das intelectuais sobre as problemáticas da população negra, construindo estéticas propositivas em que as dores poderiam ser 
traduzidas sinestesicamente por luta. Essas reelaborações colocam em cena não apenas o passado opressor, mas também reivindicações pelas existências das populações afrobrasileiras. Dessa forma, a história é reconstruída para emergir questões da contemporaneidade, fundamentada nas questões de gênero e raça (HERNANDEZ, 2006), mobilizando subjetividades enunciadas pelas corporeidades.

Nessa perspectiva, o desenvolvimento das experiências sinestésicas, por meio do filme Abolição, culminou em novos conhecimentos que questionam os currículos e as didáticas nos cursos de formação de professoras. Afinal, se grande parte dessa formação precisa romper com as perspectivas eurocêntricas, novas possibilidades de conhecimento escolar e de ensino em perspectivas decoloniais e das culturas visuais encontram outras possibilidades de respostas quando são colocadas em contato com diferentes expressividades do Movimento Negro.

Reconhecer esses poderes e reelaborá-los esteticamente desafia, de acordo com Hooks (2014, p. 183), “o modo como o poder se orquestrou nesse espaço institucionalizado em particular." Encontrar a corporeidade para ensinar permite voltar ao estado de presença no corpo (HOOKS, 2014) para reconhecer as populações das quais foram retiradas a possibilidade de se enunciarem no contexto da sala de aula.

As visualidades produzidas pelas estudantes tornaram-nas reconstrutoras contínuas dos conhecimentos do Movimento negro, agora, fundamentados nas suas condições de mulheres, negras, professoras e intelectuais. Podemos, a partir dessa nova pedagogia das imagens, fazer outras perguntas para além das liberdades ainda não conquistadas, para pensar como as mulheres negras constroem seus processos de educabilidades e nos ensinam a trilhar caminhos menos opressores por outras imagéticas.

\section{Referências}

CARVALHO, Noel dos Santos; DOMINGUES, Petrônio. Dogma Feijoada: a invenção do cinema negro brasileiro. Revista Brasileira de Ciências Sociais, v. 33, n. 96, p. 1-18, 2017.

COHN, Greice. Pedagogias da videoarte: a experiência do encontro de estudantes do Colégio Pedro II com obras contemporâneas. Tese (Doutorado em Educação) Universidade Federal do Rio de Janeiro, Rio de Janeiro, 2016.

GOMES, Nilma Lino. Relações étnico-raciais, educação e descolonização dos currículos. Currículo sem Fronteiras, v. 12, n. 1, p. 98-109, jan./abr. 2012.

GOMES, Nilma Lino. O movimento negro educador. Petrópolis: Vozes, 2017. 
GUMBRECHT, Hans Ulrich. Produção de presença: o que o sentido não consegue transmitir. Rio de Janeiro: Contraponto: Ed. PUC-Rio, 2010.

HALL, Stuart. Da diáspora: identidades e mediações culturais. Belo Horizonte: Ed. UFMG, 2003.

HERNANDEZ, Fernando. Catadores da cultura visual: transformando fragmentos em nova narrativa cultural. Porto Alegre: Mediação, 2007.

HOOKS, bell. Ensinando a transgredir: a educação como prática da liberdade. Tradução de Marcello Brandão Cipolla. São Paulo: WMF Martins Fontes, 2014.

HOOKS, bell. Olhares negros: raça e representação. Tradução de Stephanie Borges. São Paulo: Elefante, 2018.

LEANDRO, Anita. Da imagem pedagógica à pedagogia da imagem. Artigo publicado na Revista Comunicação \&Educação. p. 29-36, maio/ago, 2001.

MERCER, Koberna. Welcome to the jungle: news positions in black cultural studies. London: Routledge, 1994.

MIGNOLO, Walter. Histórias locais, projetos globais: colonialidade, saberes subalternos e pensamento liminar. Tradução de Solange Ribeiro de Oliveira. Belo Horizonte: Editora UFMG, 2003.

MIRANDA, Cláudia; RIASCOS, Fanny Milenna Quiñones. Pedagogias decoloniais e interculturalidade: desafios para uma agenda educacional antirracista. Educação em Foco, Juiz de Fora, v. 21, n. 3, p. 545-572, set./dez. 2016.

WALSH, Catherine. Interculturalidade crítica e pedagogia decolonial: in-surgir, re-existir e re-viver. In: CANDAU, V. M. (org.). Educação intercultural na América Latina: entre concepções, tensões e propostas. Rio de Janeiro: 7Letras, 2009.

Filme

ABOLIÇÃO. Direção: Zózimo Bulbul. Rio de Janeiro - RJ, 1988. 150 min

Submetido em: 19-03-2020.

Publicado em: 01-07-2020. 